\title{
Case Report: Unusual Complication Post Otoplasty
}

\author{
Fatima Al Subhi \\ Department of Plastic Surgery, Prince Sultan Military Medical City, Riyadh, Saudi Arabia \\ Email: dr_subhi@hotmail.com
}

How to cite this paper: Al Subhi, F. (2018) Case Report: Unusual Complication Post Otoplasty. Modern Plastic Surgery, 8, 1-7. https://doi.org/10.4236/mps.2018.81001

Received: September 18, 2017 Accepted: December 9, 2017

Published: December 12, 2017

Copyright $\odot 2018$ by author and Scientific Research Publishing Inc. This work is licensed under the Creative Commons Attribution International License (CC BY 4.0).

http://creativecommons.org/licenses/by/4.0/

\begin{abstract}
Otoplasty is very commonly used for the surgical correction of prominent ears. This procedure generally does not involve major complications. Pain and itching, hematoma and bleeding and infection are the most common complications generally observed in post otoplasty patients. We present a case of a 13 years old boy who showed abnormal swelling from the pre- to the post-auricular area throughout the temporal region one day after the surgery. This case is distinct as the swelling was without the involvement of active bleeding but hematoma like complication at the site of surgery. The investigations were undertaken and the probable cause for these unusual observations were most likely related to lymphatic malformation.
\end{abstract}

\section{Keywords}

Otoplasty, Unusual Complication, Swelling, Pre-Post Auricular Area, No Hematoma, Lymphatic Malformation

\section{Introduction}

The prominent ear is a congenital deformity that can affect the psychology of a child. It affects around 5\% of the population [1]. Otoplasty, the procedure commonly performed to correct protruding ears, usually shows a good outcome with a positive influence on the psychology of the children. The shape, position and proportion of the ear can be improved through the use of this technique. The procedure is safe but associated with complications. In a recent review on the outcomes of otoplasty, Sadhra et al. [2], observed that pain and itching were the most commonly observed complications after otoplasty, followed by revision surgery/recurrence (5\%), skin wound healing problems (3\%), hematoma and/or bleeding (2.5\%), suture-related problems (1.8\%), scarring (1.6\%) and infection $(0.8 \%)$. On the other hand, complications such as temporal nerve paresis [3], 
meatal obstruction [4], and Ramsay Hunt syndrome [5], have also been reported following otoplasty. We present a case of unusual swelling at the pre- to the post-auricular area throughout the temporal region one day after otoplasty without any hematoma or active bleeding at the site of surgery in a healthy child after ear deformity surgical correction.

\section{Case Report}

A 13 years old healthy boy presented with a bilateral congenital ear deformity. In the very early childhood of the patient, a congenital posterior auricular mass with unknown diagnosis was excised from the right ear. Clinically the child presented was unhappy with the shape of his right ear deformity. The clinical features showed a low set ear, lidding, prominence of the concha and bilateral protrusion that was more significant on the right side (Figure 1 and Figure 2). The other dominant facial features included the down-slanting eyes with low dorsum nasal bridge.

Surgically the patient was subjected to lidding deformity excision, the root of helix rotation, and finally with concha mastoid suturing. Post-auricular skin excision (Furans technique) and Mustard were used to address the prominence

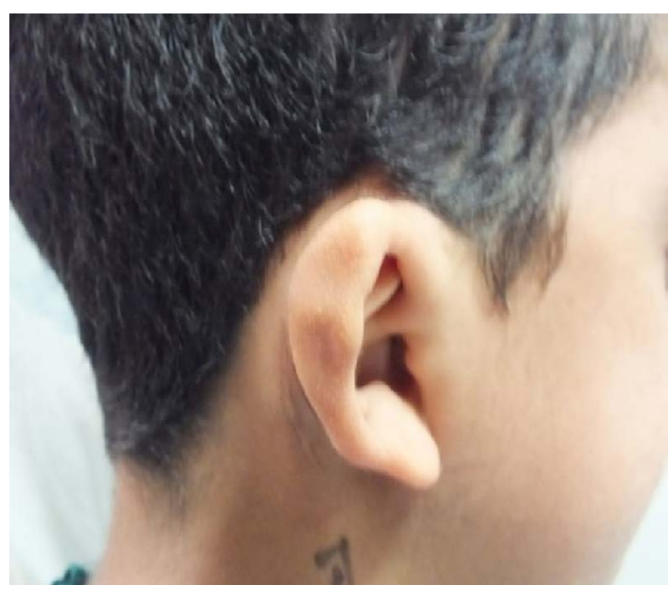

Figure 1. Lateral view of right constricted ear deformity.

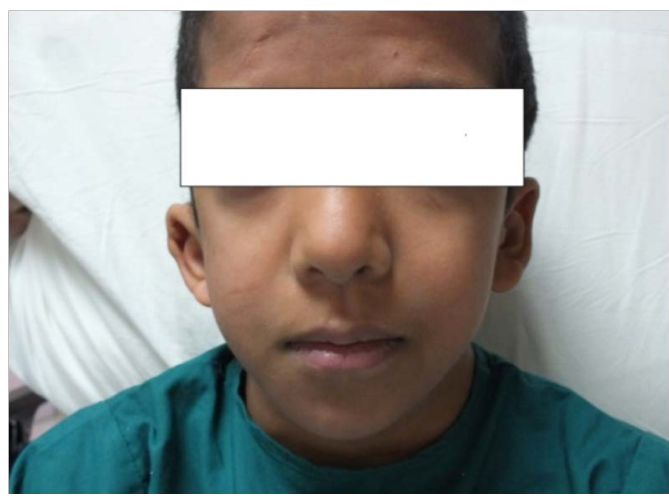

Figure 2. Frontal view preoperatively. 
(Figure 3). There were no intraoperative complications or bleeding and the wounds were closed with secured hemostasis and reinforced with bolster pressure and headband dressing was applied.

On the first day postoperatively, the patient complained of mild pain and extensive swelling extending from the pre to the post-auricular area throughout the temporal region, and unexpected swelling over the operated site of the external ear (Figure $4 \&$ Figure 5). There was no redness, inflammation or continuous bleeding from the site of the wound. The dressing was dry with old blood

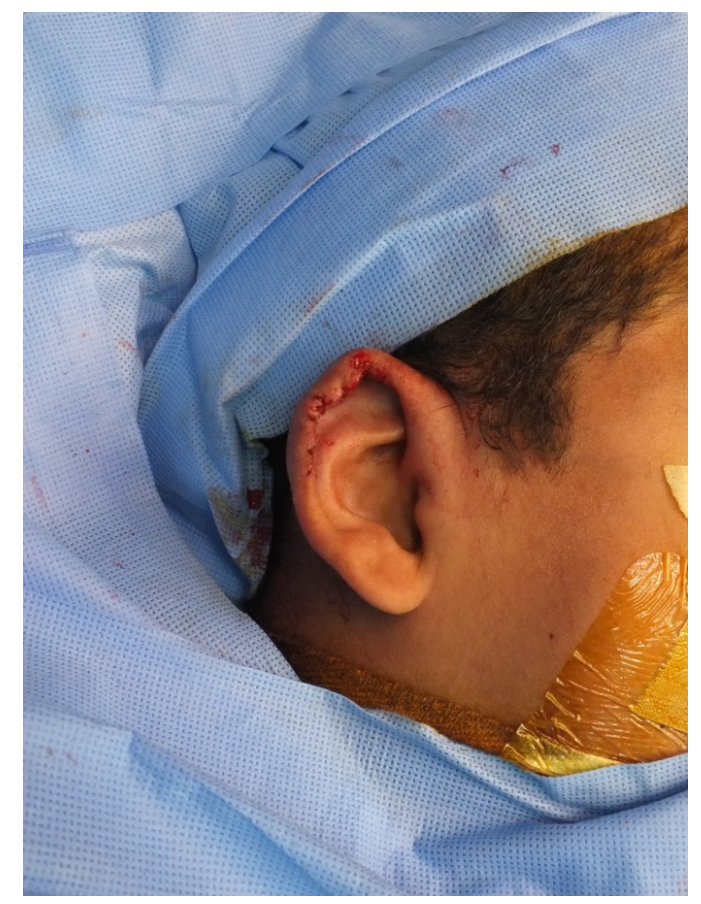

Figure 3. Immediate post-operative picture.

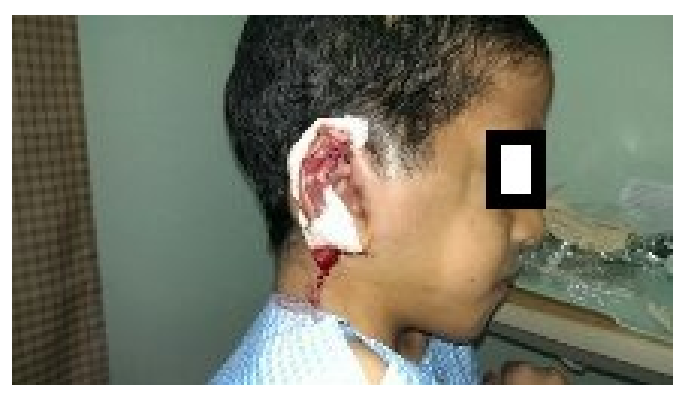

Figure 4. Preauricularand temporal swelling.

stains on the skin. The patient was kept under observation as it was diffuse swelling with no localized or well-defined hematoma like collection. A radiological Ultrasound showed an extensive edematous change around the ear and swelling of temporalis muscle with cystic configuration (Figure 6). There was no hematoma or any collection. On the following day, there was a mild improvement with anti-inflammatory treatment. More investigations were requested including 


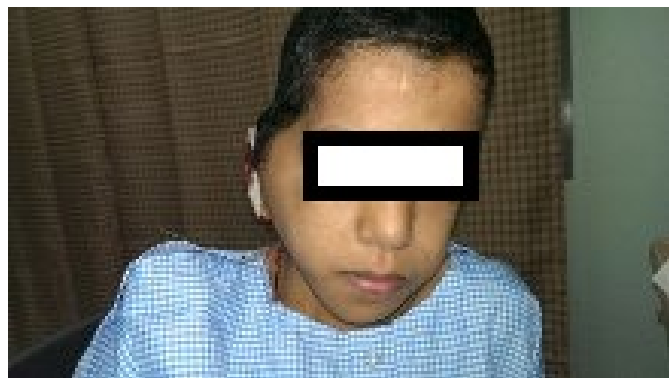

Figure 5. First day post operative with preauriclar unoperated side swelling.

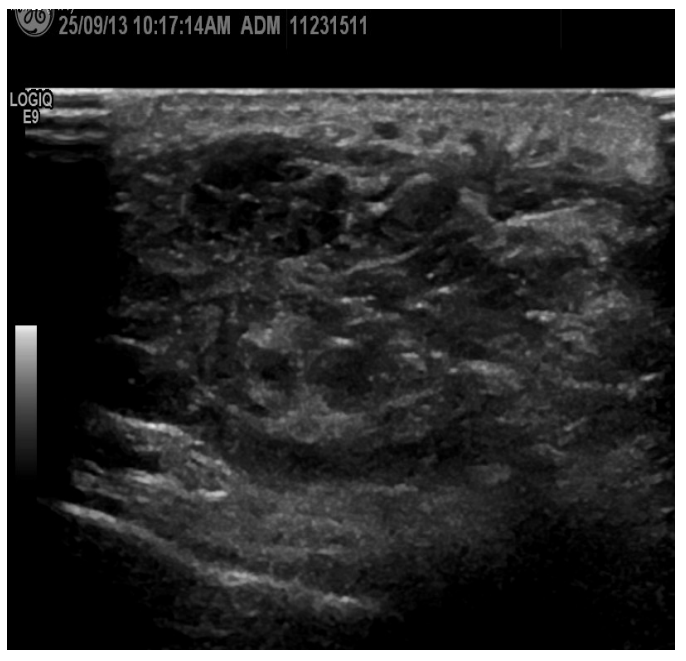

Figure 6. Right preauricular area (non-operated) with cystic encapsulated swelling.

Ristocetin cofactor test, coagulation profile and Immunoglobulin. Tissue was collected for histopathology examination.

Computerized tomography scan on that day showed a mix of iso and hyper density features in the peri-auricular areas and a large right temporal and peri-auricular soft tissue lesion (Figure $7 \&$ Figure 8). The hyperdensities are likely representing large hematomas in the post-auricular area (Figure $7 \&$ Figure 8). Interestingly small pockets of air were also seen within the lesion, however, no evidence of sizable fluid collections or abscess formation could be noted. The reopening of the surgical site revealed a blood-stained fluid, a huge swelling of the dermis layer with small multi-cysts with hemo-serous fluids but no well-defined collection could be found. Conchal mastoid sutures were in place with no collection occupying the space but the dermis was thickened $(1.5 \mathrm{~mm})$ with cystic configuration (Figure 9). There were no bleeding vessels so cauterization was not required. Since a clear diagnosis could not be reached the wound was closed.

The swelling subsided over the next few days, the patient recovered very well. Histopathology examination showed fibro-adipose tissue with extensive focal dilated lymphatics and mild dispersion of acute inflammatory cells. These findings 


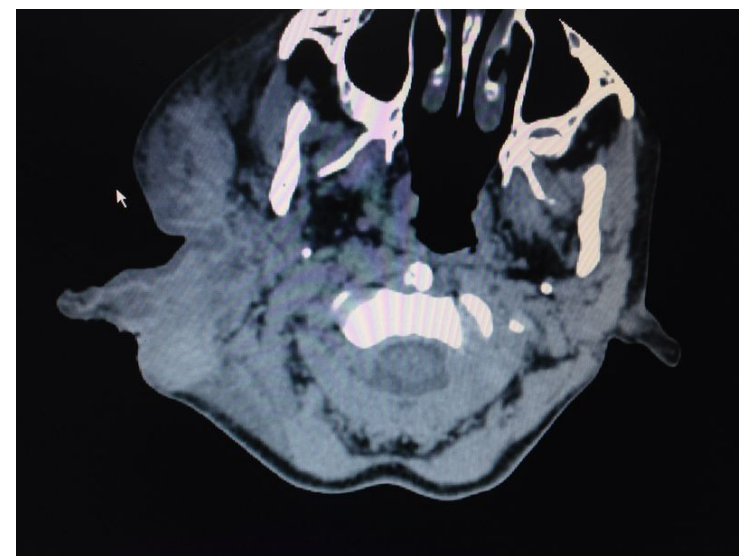

Figure 7. Computed Tomography scan of head with diffuse swelling in periauricular area with hyperdensity postauricular with a hematoma like swelling.

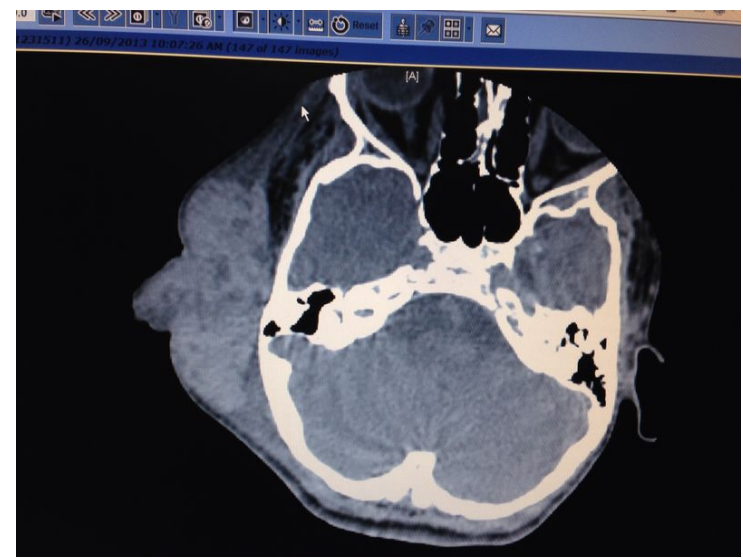

Figure 8. Computed Tomography scan showing a unified density swelling in all the periauricular area.

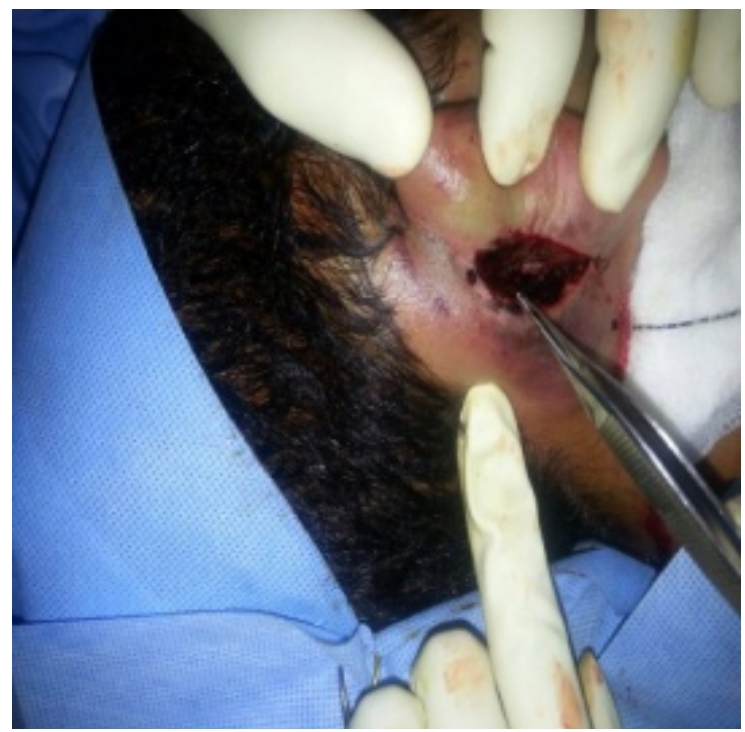

Figure 9. Intraoperative multicystic dermis filled with hemoserous fluid (atypical hematoma). 
were consistent with our clinical suspicion of extensive lymphatic channels a remnant of the unknown mass that was removed in his childhood which developed similar complications and when reopened showed no definite diagnosis at that stage.

\section{Discussion}

Generally, the complications following otoplasty include hematoma recorded in around $2.2 \%$ of the patients [6]. The hematoma usually develops in early post-surgery hours mostly due to the rebound vasodilatation effect of the local anesthesia [7]. The hallmark sign of the postoperative hematoma is intense pain, bluish discoloration of the skin, and bleeding with soaked dressing within 24 hours postoperatively [8], which is not consistent with the observation made in this case. The swelling observed in this case appeared on the following day and observed by the physician. In addition to that, the main leading sign of hematoma or any bleeding is normally distributed in an asymmetrical fashion or unilaterally, which was also not observed in this case.

A bluish discoloration of the skin started to appear later and mandate the exploration only in the second day from the surgical day. The swelling appeared awkwardly in the non-operated pre auricular, and the temporal region as well and was not accompanied by any bleeding or oozing, thus ruling out hematoma as the cause of the swelling.

The patient was not known to have any bleeding diathesis and investigated thoroughly for any syndromes or any congenital illness. Moreover, all the diagnostic investigations of the ultrasound and the CT were inconclusive for the formation of a hematoma. The investigations suggested the presence of cystic channels filled with fluids and blood. Histopathology of the post-auricular tissues showed extensive lymphatic channels and inflammatory cells most likely as remnants of dilated lymphatic malformations and presence of fibrous adipose tissue filled with blood and serous. These observations are suggestive of the involvement of the lymphatic channels for the observed swelling at the pre- and post-auricular areas and the temporal region after otoplasty.

\section{Conclusion}

This is an unusual case of extensive swelling extending from the pre- to the post-auricular area throughout the temporal region of post otoplasty without any indication of a hematoma or bleeding. The investigations suggest the involvement of dilated lymphatic channels. The outcome of this case suggests that children with an earlier surgery and removal of the auricular mass may be susceptible to an abnormal swelling in the pre- to post-auricular areas post otoplasty.

\section{References}

[1] Pawar, S.S., Koch, C.A. and Murakami, C. (2017) Treatment of Prominent Ears and 
Otoplasty: A Contemporary Review. JAMA Facial Plastic Surgery, 17, 449-454.

[2] Sadhra, S.S., Motahariasl, S. and Hardwicke, J.T. (2017) Complications after Prominent Ear Correction: A Systematic Review of the Literature. Journal of Plastic, Reconstructive \& Aesthetic Surgery, 70, 1083-1090.

https://doi.org/10.1016/j.bjps.2017.05.033

[3] Kayabasoglu, G. and Nacar, A. (2015) An Unexpected Otoplasty Complication: Temporal Nerve Paresis. Aesthetic Plastic Surgery, 39, 114-116. https://doi.org/10.1007/s00266-014-0416-1

[4] Toplu, Y., Toplu, S.A., Sapmaz, E. and Deliktas, H. (2014) An Unusual Cause of Conductive Hearing Loss: Bilateral Complete Meatal Obstruction Following Otoplasty. The Journal of Craniofacial Surgery, 25, e168-e170. https://doi.org/10.1097/SCS.0000000000000494

[5] Lima, M.A. and Negreiros Jr, J.D. (2011) Ramsay Hunt Syndrome Following Otoplasty. Brazilian Journal of Otorhinolaryngology, 77, 808.

[6] Limandjaja, G.C., Breugem, C.C., Mink van der Molen, A.B. and Kon, M. (2009) Complications of Otoplasty: A Literature Review. Journal of Plastic, Reconstructive \& Aesthetic Surgery, 62, 19-27. https://doi.org/10.1016/j.bjps.2008.06.043

[7] Owsley, T.G. and Biggerstaff, T.G. (2009) Otoplastycomplications. Oral and Maxillofacial Surgery Clinics of North America, 21, 105-118. https://doi.org/10.1016/j.coms.2008.10.011

[8] Handler, E.B., Song, T. and Shih, C. (2013) Complications of Otoplasty. Facial Plastic Surgery Clinics of North America, 21, 653-662.

https://doi.org/10.1016/j.fsc.2013.08.001 